\title{
A práxis do viver como epistemologia: o saber sentido da/na escola como forma de emancipação da condição humana no viver na terra
} The praxis of living as epistemology: the sense of knowledge in school as a form of emancipation of the human condition in living on earth

\author{
Cláudia Moraes da Costa Vieira ${ }^{1}$ e Cláudia Pato². 1. Secretaria de Educação do Distrito \\ Federal. 2. Universidade de Brasília-UNB (Brasil)
}

\begin{abstract}
Resumo
Estudos têm demonstrado a ausência da instituição escolar na trajetória de vida de grupos empobrecidos como o dos catadores de material reciclável. O objetivo do trabalho foi compreender as trajetórias de vida e os processos escolares de estudantes filhos de catadores de material reciclável de uma escola pública do Distrito Federal-DF, localizada no Brasil. Propôs-se o método autoecobiográfico, centrado em oficinas, observação participante e o diário de campo, baseando-se na fenomenologia e na hermenêutica para as análises do processo. Participaram 65 estudantes do $4^{\circ}$ ano do ensino fundamental. Pode-se inferir que a sobrevivência e a vivência no Aterro sanitário apontam para a degradação socioambiental e do trabalho, mas assinalam a complexidade do encontro da preca riedade e da criatividade. A família é o território das relações afetivas, onde trabalho e vida se entrelaçam. A escola emerge como território de contradição, mas aponta a existência de elementos de positividade. O pertencimento ao lugar, em que símbolos, relações e histórias se instituem como elementos fundantes para autobiografias e para a biografia coletiva. Destaca-se, portanto, a importânciada escuta desses estudantes pela escola para a constituição de utopias baseadas em autoeducação, autoconsciência e autonomia como um modo de reconectar a educação escolar à vida. .
\end{abstract}

\section{Astract}

Studies have demonstrated the absence of the school institution in the life trajectory of impoverished groups such as recyclable material collectors. The objective of this work was to understand the life trajectories and the school processes of students who are children of recyclable waste pickers of a public school in the Federal District, located in Brazil. It was proposed the autoecobiographic method, centered in workshops, participant observation and field diary, based on phenomenology and hermeneutics for the analysis of the process. 65 students participated in the 4 th year of elementary school. It can be inferred that survival and living in the landfill point to socioenvironmental degradation and work, but they point to the complexity of the encounter of precariousness and creativity. The family is the territory of affective relationships, where work and life intertwine. The school emerges as a territory of contradiction, but 


\begin{abstract}
points to the existence of elements of positivity. Belonging to the place, where symbols, relationships and stories are established as founding elements for autobiographies and for the collective biography. Therefore, the importance of listening to the students for the formation of utopias based on selfeducation, self-consciousness and autonomy as a way to reconnect school education with life is emphasized. Palabras chave

Catadores de material reciclável; Educação Ambiental; Ecologia Humana; Método autoecobiográfico; Trajetória de vida.
\end{abstract}

\title{
Key-words
}

Recyclable waste pickers; Environmental education; Human Ecology; Autoecobiographic method; Life trajectory.

\section{Introdução}

Buscar sentidos para compreender o ser humano e suas relações, intervenções e significados atribuídos à existência, remete-nos ao desejo de compreender a constituição de outros seres, de nós mesmos, em busca do autoconhecimento e, simultaneamente, a constituição da possibilidade de vivenciarmos o encontro com a humanidade que nos habita.

Assim, para o encontro com o saber sentido, produzido na relação do sujeito com o espaço escolar, faz-se necessária a construção da possibilidade de olhar para a escola como um território, e defini-la como um lugar constituído por diversas histórias. Pereira (2008) compreende que a escola se insere na perspectiva de território, quando se busca enxergá-la como um lugar que produz identificação, gerada pela experiência entre os seres e o local. É a concepção de que os espaços e, os lugares existem em função dos sentidos e dos valores que as pessoas foram atribuindo a eles, no decorrer de sua existência, das histórias que foram construídas.

Para propor um olhar sobre as trajetórias de vida e os processos escolares dos estudantes filhos de catadores, é necessário considerar que os processos escolares são compreendidos como o viver e o conviver, individual e coletivo, desses estudantes, no decurso de seus percursos escolares. São questões concretas e subjetivas, vivenciadas a partir das diversas relações estabelecidas no território escolar.

Com base em tais reflexões, foram levantadas as seguintes questões de pesquisa: a) quais são as compreensões que os estudantes, filhos de catadores de material reciclável, têm de suas trajetórias de vida e de seus processos escolares? b) De que forma eles compreendem a escola, a constituição de si e a do grupo a que pertencem? c) De que modo os saberes, valores e sentidos advindos da história de vida desses estudantes são reconhecidos pela escola? 
Neste sentido, o estudo buscou compreender as trajetórias de vida e os processos escolares dos estudantes filhos de catadores de material reciclável de uma escola pública do Distrito Federal-DF, com o uso do método autoecobiográfico.

Para o alcance desse objetivo geral foram elaborados os seguintes objetivos específicos: analisar as trajetórias de vidas e os processos escolares dos estudantes a partir das narrativas de vida; identificar articulações entre as trajetórias de vida e os processos escolares dos estudantes; conhecer o olhar que os estudantes lançam sobre si, para a escola e para o grupo ao qual pertencem, a partir de suas trajetórias de vida e dos processos escolares vivenciados; investigar qual a percepção da escola sobre os saberes, valores e sentidos advindos da história de vida desses estudantes.

O estudo adotou como caminho teórico metodológico a constituição e a análise pessoal e coletiva das histórias de vida e dos processos escolares de estudantes filhos de catadores de material reciclável e, concomitantemente, a constituição de um espaço de auto formação e de intervenção, para os atores envolvidos no processo, com a inclusão dos professores regentes dos respectivos grupos, a gestora da instituição de ensino, como para esta pesquisadora.

Utilizou-se as estratégias: oficinas autoecobiográficas, observação participante, entrevistas semiestruturadas e roda de conversa. Optou-se pela análise interpretativa ancorada na abordagem fenomenológica-hermenêutica. Baseou-se na análise interpretativa -compreensiva de Paul Ricoeur (1994) e na leitura dos três tempos baseadas nos trabalhos de SouzA (2004): Leitura Cruzada e Pré-análise, Unidades de análise temáticas e descritivas e Leitura interpretativa e compreensiva.

O presente estudo foi realizado na Escola Classe 01 da Cidade Estrutural, escola pública do Distrito Federal pertencente a Secretaria de Estado de Educação do Distrito Federal - SEDF, localizada no Brasil. A escolha por esta escola se deu devido a sua localização, a Cidade Estrutural e ou "Vila Estrutural", e lá se encontrar o Aterro Sanitário que recebe diariamente os resíduos do Distrito Federal, bem como estão presentes os catadores que trabalham de forma independente e aqueles organizados em cooperativas.

Neste sentido, foram definidos quatro critérios para a escolha dos participantes estudantes: ser filho de pessoas que exerciam a ocupação de catadores de material reciclável; estarem cursando o $4^{\circ}$ ano; aceitarem ser voluntários na pesquisa; terem a autorização dos pais e de seus professores para participarem da pesquisa. Assim, a pesquisa foi realizada com 65 estudantes, com média de idade de 10,75 anos (35 meninas; 30 meninos), dos quais 36 residem na Ocupação Santa Luzia e 29 na Estrutural. 
Nesse universo de 65 famílias, 41 delas possui a mesma escolarização dos estudantes envolvidos nesse estudo, em alguns grupos, eles são os que apresentam a maior escolarização do núcleo familiar, isso revela o processo de exclusão deste referido grupo na perspectiva da educação formal.

A gestora e os cinco professores regentes dos estudantes foram participantes da pesquisa, para se buscar uma melhor compreensão do contexto escolar e um diálogo permanente com o processo da pesquisa.

Dessa forma, ao relatarem suas trajetórias de vidas e ao mesmo tempo refletirem sobre o espaço escolar, pode-se constatar que os estudantes vão identificando outros colegas que também vivem nas mesmas condições, o que contribui para o fortalecimento de sua identidade pessoal e coletiva e permite criar laços afetivos e potencializá-los. .

\section{Os sentidos da \\ sobrevivência e da vivência no Aterro Sanitári}

As histórias e os contextos vão dando movimento às narrativas dos estudantes, constituindo territórios como o Aterro Sanitário, esse se constitui como um ponto de referência, como um território simbólico em que eles vão construindo relações com o lugar e com tudo que o compõe. Uma etapa no decorrer das oficinas autoecobiográficas que denominamos de "problematização das narrativas" trouxe a necessidade de dialogar sobre o contexto do filme: O Menino Urubu, em que eles trouxeram na sua essência o significado do olhar reflexivo sobre o Aterro Sanitário.

Alguns foram elencando como "um monte de lixo" e/ou uma "montanha de lixo", que permitia se manter aceso o fogo de forma permanente e que serviria como fogão ou "fogareiro" para vários catadores que precisavam aquecer o alimento diariamente. De forma consciente, os colaboradores, ao narrarem sobre essa luz, argumentavam que ela se originava o efeito do gás metano. Um lugar no qual convivem os catadores no trabalho com a reciclagem, mas também em que se encontra a violência e os diversos acidentes no interior do Aterro.

Ao iniciar a narração autobiográfica estabelece-se o primeiro contato com o personagem Carniça, como estratégia utilizada para a aproximação do contexto dos estudantes. Alguns colaboradores ao ouvirem a expressão Carniça, nome dado ao personagem, o vão identificando como algo que os faz sentir a sensação de nojo, aversão. Concomitantemente, relacionam o nome a algo engraçado e incômodo no sentido de uma sátira, utilizada por alguns estudantes, que justificam serem dessa 
maneira que algumas pessoas denominam aqueles que são filhos de catadores de material reciclável, as pessoas que trabalham no Aterro Sanitário e com o processo de reciclagem.

Reconhecem o contexto, mas buscam estratégias de negarem as relações de proximidade com suas próprias histórias. Vão narrando a partir da história de outras pessoas e ou eventos vinculados na mídia. Usam como exemplos notícias acontecidas. São as histórias de outras pessoas que trabalham no Aterro Sanitário que são articuladas ao contexto inicial da conversa.

Maria (10 anos): "tia eu conheço um menino que trabalha lá, a mãe dele não trabalha, ela fica olhando os filho dela, acho que tem 12 ou 10 não sei? Ele vai trabalhar reciclando e depois vende o material e pega o dinheiro quando a mãe dele precisa, ele pega e dá".

$\mathrm{Na}$ voz da Maria, é desvelada a situação de crianças que ainda trabalham no Aterro sanitário para manter a renda de suas famílias. Pela referência dada à idade, pode-se concluir que é uma criança em idade escolar, mas, devido a vulnerabilidade social familiar, coloca-se como mais um do núcleo familiar a empenhar-se pelo sustento financeiro. O trabalho infantil é revelado como uma das formas de degradação do trabalho e da pessoa criança, como consequência do capitalismo e é, de certa forma, naturalizado em áreas vulneráveis como no Aterro Sanitário.
Eles reconhecem que há o trabalho infantil, mas veem como uma forma de colaboração na família e mostram que esse modo de trabalho, pode trazer de forma mais rápida o retorno monetário. Nas pesquisas como de CaVAlCANTE (2014), essa condição pode ser a que atrai as crianças em situação de vulnerabilidade para o trabalho no Aterro Sanitário, a possibilidade de se receber o valor do trabalho na hora da entrega do material.

Trazem um olhar de cuidado e preocupação no sentido de trazer como referência a lagoa de chorume. Ao relatar, definem a compreensão sobre esse fenômeno. De acordo com a sua compreensão, o Aterro poderia ser definido pela lagoa de chorume e os processos de violência que ocorrem naquele lugar. Outro aspecto observado é o estereótipo construído da pobreza. O faz, para que não seja revelado o seu conhecimento daquela realidade, pois conhecer naquele momento, com detalhes, o Aterro Sanitário, era uma confirmação da sua relação com os catadores.

As narrativas vão revelando a dificuldade que eles têm de trazer elementos próprios dessa realidade, descrevem o lugar, contudo, lentamente, começam a incluir nomes de parentes próximos como tios, padrinhos, madrinhas e vizinhos. Descrevem histórias de outras crianças e pessoas que trabalham no Aterro sanitário, ausentam-se de afirmações, mas revelam que conhecem de forma autêntica o modo de 
vida daqueles que sobrevivem dos lixões e o cenário cotidiano daquele lugar.

A questão vai se convertendo quando eles têm a possibilidade de expressar os pontos significativos daquele encontro por meio do desenho em seus diários de campo. Nesse momento observa-se que relatam ao grupo a rotina do trabalho do Aterro Sanitário e interagem de forma coletiva a partir dessa discussão. A conversa abre espaço para confidências "ao pé do ouvido" e a outras conversas que são expressadas em voz alta e confirmadas pelo grupo. A imagem 1 e 2 recorda essa confirmação.

Os desenhos foram mostrados ao grupo pelo colaborador e alguns comentavam que os urubus estavam em tamanho pequeno, diante aos que habitavam o local. A árvore representada dentro do Aterro Sanitário trouxe indagações de alguns, mas para o João representava o desejo de ter ali um local "com sombras" para que os catadores pudessem descansar.

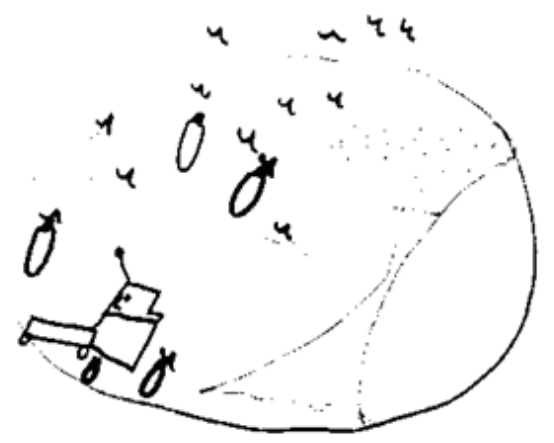

Imagem 1: O Lixão. Fonte: Desenho de João, 12 anos
Josué lembrava a quantidade de carretas que circulava no lixão em todos os períodos. Esses desenhos buscaram materializar o que para eles era mais visível no Aterro Sanitário o, no caso de Josué, era o que mais o afetava, pois a quantidade de carreta o deixava preocupado devido aos acidentes que eram ocasionados ali quase que diariamente.

Percebeu-se que, ao expressarem suas impressões a partir do registro do desenho, foram tornando-se livres e construindo um espaço de liberdade para trazer as questões subjetivas. Aqui a manifestação artística do desenho infantil rompeu o espaço do silêncio, trouxe elementos da realidade, do cotidiano, mas veio acompanhada da imaginação na perspectiva do sonho de se ter, naquele local, espaços para o descanso de seus pais. O desenho das carretas era uma forma de expressar o sentimento da insegurança e da dor que o movimento demasiado daqueles transportes ocasionava entre eles. Alguns estudantes colaboradores se aproximavam e contavam histórias ocorridas no Aterro Sanitário e outros ainda faziam gestos para que o colega confirmasse a sua ver-

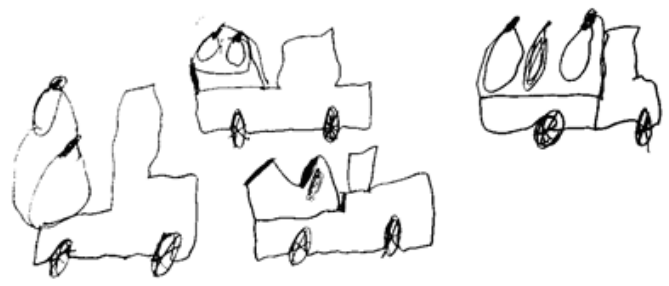
Imagem 2: As carretas do Lixão. Fonte: Desenho de Josué, 12 anos 
são. Nesse exercício dialógico, trouxeram memórias dos momentos do trabalho, relações com seus pais e avós, histórias que retratavam o Aterro Sanitário em um tempo passado.

Essas expressões iam legitimando a condição de filhos de catadores e visibilizando esses seres. lam afirmando a condição de filhos de catadores e pertencentes àquele contexto. A condição os fazia trazer a voz para o diálogo. Isso os permitia identificar o local de habitação, as "casinhas", como as denominavam e as caracterizavam. Essas representações inclusive revelavam a hierarquia existente entre os moradores das casinhas, da Ocupação da Santa Luzia e da Cidade Estrutural.

As casinhas eram denominadas como as casas de tijolo e madeira onde os catadores moravam e, por isso, justificavam a proximidade do lixão. A Santa Luzia era definida como sendo um local um pouco longe da entrada principal do lixão, como o Centro da Cidade Estrutural. Por isso, ela era considerada como a Cidade Estrutural, mesmo com a falta de infraestrutura na Ocupação Santa Luzia, eles consideravam um lugar melhor para se habitar. Outro elemento era o fato das "casinhas" serem as casas dos catadores e toda a comunidade ter esse conhecimento. Isso dava ao local um status de menor aceitação por eles. Essas diferenças iam agregando valores às condições da moradia.
A negação da condição de filhos de catadores foi compreendida como uma relação de cuidado consigo, uma autoproteção, no sentido de se protegerem para não serem ofendidos, e/ou machucados por seus pais serem catadores e trabalharem no Aterro Sanitário. Essa voz se apresentou em vários subgrupos, mas não se legitimou no universo coletivo, pois havia outro grupo que já nos primeiros encontros, assumiu essa condição. Ao passo que iam se fortalecendo, iam verbalizando, alguns com segurança, outros de forma tímida e ainda cabisbaixos:

Utilizavam o termo vala para identificar o lugar em que seus pais trabalham no Aterro Sanitário. Mesmo não sendo a maioria, esse pequeno grupo de crianças revelou a profissão dos seus pais. Conscientemente, assumiram as consequências desse ato para a escola e para a comunidade, pois perceberam a presença de outros naquela condição. Assim, como a Mariana, que foi se apropriando de suas histórias para estabelecer o pertencimento àquela realidade, eles foram se apropriando da tomada de consciência no processo de refletir sobre o vivido e de identificar um grupo que os fortalece.

No decorrer, foi revelada uma diferença dos relatos entre aqueles que os pais trabalhavam no Aterro Sanitário de forma independente e aqueles que os pais tinham filiação a alguma Cooperativa. Esses que pertenciam a uma instituição organizada 
ao falarem expressavam que seus pais não trabalhavam no Aterro diretamente, somente aleatoriamente. A partir daí, iam agregaram elementos do cotidiano individual e coletivo e articulando ao passado, ao presente e trazendo perspectivas de futuro ao cenário do Aterro Sanitário.

O Aterro Sanitário vai sendo descrito a partir de elementos que dão sentido a todo o cenário social, histórico, cultural e ambiental e revelando um trabalho que é exercido por famílias, como demonstram os relatos autobiográficos. Mais uma vez, verifica-se o trabalho de adolescentes e crianças no Aterro. Esses elementos trazem uma carga de questões subjetivas da trajetória individual e coletiva dos colaboradores estudantes e vão se aproximando do contexto local e constituindo a comunidade dos que trabalham naquela área.

Demonstraram a preocupação da distância entre as casas e a lagoa de chorume no sentido de demonstrar as consequências da localização do Aterro para toda aquela comunidade e para aquele solo. Esta preocupação vinha acompanhada com a quantidade de lixo e a forma desordenada de como ele era armazenado. A quantidade de carretas e os vários acidentes que ocorriam ali eram outro ponto que gerava discussão e preocupação entre os colaboradores. Isso tornava-se mais delicado quando incluía parentes próximos como: mãe, pai, avó, irmãos e também amigos e conhecidos. Essa era uma afirmação re- corrente e angustiada, que demonstrava a incapacidade e a dificuldade de visualizarem possibilidades de mudanças para esta situação.

Era observável na expressão de seus rostos, no tom dos relatos. Essa situação iria se perpetuar ainda por um processo grande de tempo ou enquanto houvesse pessoas trabalhando daquela maneira. A velocidade das carretas e tratores que circulavam por lá era um ponto de preocupação:

Tomás (11anos): Lá tem um trator passando toda hora. Máquina de amassar o lixo. As carreta leva. Tem que pegar logo, se não enterra.

Luzia (10anos): Lá no lixão. Foi na Cuca. É onde a mulher trabalha. A mulher nem mexia.

Tomás revela uma das principais causas dos vários acidentes que ocorrem no lixão, a diferença da velocidade entre o homem e a máquina. Quando o lixo era jogado nos espaços de destino, vários catadores estavam lá para coletar e separar. Contudo, essa ação precisava ser veloz, pois, logo após, viria o trator para enterrar e isso era uma das causas dos acidentes ocorridos como os citados pela Luzia. Nos relatos, estabelecia-se um saber consciente sobre a realidade na qual estavam inseridos. Demostravam uma capacidade reflexiva e crítica de olhar a realidade e apontar questões necessárias e perceptíveis para 
as mudanças, mas também reconheciam a limitação que tinham, pois seus pais precisavam continuar naquele trabalho para manter suas famílias por uma situação de sobrevivência.

Amadeu (12 anos) O meu pai é da cooperativa, lá de Brasília. As vez o caminhão da SLU vai levar o lixo lá, aí eles separo. Ele não preciso ir no lixão, mas as vez ele e os catador de lá vai, quando o caminhão demora ai.

A diferença mostrada revelou a dificuldade do processo de coleta seletiva no Distrito Federal, onde não há uma continuidade na entrega desse material nas cooperativas, o que faz com quê alguns dos catadores ainda tenham que ir ao Aterro Sanitário nos períodos em que o caminhão não faz a entrega do material. O Aterro Sanitário está presente tanto para aqueles que trabalham independente, como para aqueles vinculados a cooperativas e associações, mas que não conseguem estabelecer uma rede de coleta, já que a do Estado ainda se encontra em situação de fragilidade no sentido de uma política prática sobre os resíduos.

Ao narrarem, iam se misturando o Aterro Sanitário e à Cidade Estrutural, os sofrimentos e dores dos que trabalham na catação, dentro do Aterro, com o sofrimento dos que moram na cidade, devido aos impactos ambientais produzidos pela localização do lixão.

\section{A família : os laços e nós}

A família vai se apresentando aos poucos, a partir da afirmação de serem filhos de catadores de material reciclável. Revelam que pertencem a um grupo em que trabaIho e vida se entrelaçam. Identifica-se ali uma base de apoio e segurança para a grande maioria. Em outros casos a ausência dessa base é, revelada por pais e mães que parecem ser filhos, pela circunstância da idade e também do processo de exclusão que ainda vivenciam.

A família vai se constituindo nesse território, em que se aprende desde cedo o valor de se contribuir uns com os outros, a participar da luta coletiva pela sobrevivência. Diante de diversas ausências, que se estendem à falta de alguns membros, como os pais e irmãos mais velhos, esses estudantes precisam se mobilizar para aprender a suprir e criar formas de preencher esse vazio.

O trabalho é um dos elementos que constitui uma base de relação desse grupo familiar, no qual filhos e pais vivenciam diariamente o contexto dos que sobrevivem da catação. O cuidado que demonstraram nos relatos em que evidenciavam o trabaIho dos pais, demonstra a relação entre o trabalho e o viver desses estudantes. A narrativa se constituía como exercício árduo, em especial nos primeiros momentos, quando não haviam estabelecido o 
clima de confiança entre os participantes, entre eles e a pesquisadora.

Alguns estudavam na mesma sala de aula, mas não falavam muito de si. Outros se encontravam fora da escola, no Aterro, onde seus pais trabalhavam. Demonstrava-se certa cumplicidade e, intimidade, o que os levava a ficarem mais próximos na sala de aula e a constituírem pequenos grupos.

Antônio (11 anos): tia, eu e o Tadeu sai daqui e vai catar latina, né? A gente entra lá pelo campo. Né? (Sorrir muito).

Tadeu (11 anos): hoje tenho que pegá peti também. Tia onti nós achou um monte (faz gestos com as mãos).

Esses grupos ou duplas estavam sempre próximos. Eram contextos muito próximos que não poderiam compartilhar com todos os colegas, iam se agrupando como forma de fortalecimento e espaço de amizade.

Para esses estudantes que vivenciam conflitos e contradições desde muito cedo, o trabalho exercido por seus pais, de catar no Aterro os resíduos sólidos, como maneira de garantir o sustento da família, parecia revelar sentimentos simultâneos de orgulho e vergonha conforme ilustrado na fala a seguir.

Kédma (10anos): Tem muita gente, assim que trabalha de catadora e tem muito filho assim, que tem vergonha de ter uma mãe catadora, mas eu não tenho, tenho muito orgulho de ter a minha catadora, ela me dá tudo, me dá boneca, me dá as coisas, assim se não fosse por ela eu não estaria na escola.

A Kédma eleva a voz ao falar de sua mãe. $O$ relato revela a dualidade entre o sentimento relacionado ao orgulho, pois é a partir do trabalho de catação que sua mãe garante o sustento de toda a sua família, a manutenção material, e o suporte da formação, pois é a partir dela e do trabaIho que há um vínculo ao valor atribuído à educação, ao processo do acesso a escola. Também há destaque ao cuidado revelado pela infância. Mesmo no meio de um trabalho que se exige atenção e cautela para se desviar dos acidentes, a mãe se preocupa em trazer-Ihes brinquedos.

Joana lembrou que há um valor ambiental no trabalho de sua mãe:

Joana (10 anos): Eu acho esses negócio de reciclagem são muito bom pro meio ambiente, mas a pessoa não cuidam do Meio Ambiente, joga lixo na rua . Eu também achei bom minha mãe fazer esse trabalho, por que ela vai me ensinando como recicla as coisas [...].

Mais uma vez a figura materna é citada. Joana compõe sua narrativa em um tom de segurança. O relato ilustra a aprendizagem que constroem com os pais, das contribuições de seus trabalhos para a vida individual e das cidades. A reciclagem vai sendo apropriada por todo o núcleo familiar e constituindo saberes e fazeres próprios da especificidade da catação. 
Esses aspectos também são identificados nos trabalhos de Barbosa, (2012), Teixeira (2010) e Alterthum, (2005). Trata-se de um saber advindo do viver e sobreviver da reciclagem. Percebe-se um vínculo entre o trabalho da reciclagem e o cuidado com meio ambiente, como forma de amenizar o dano causado pelo acúmulo e produção de resíduos nas cidades, mas simultaneamente, sugere-se um olhar de desaprovação das pessoas e da sociedade, ao demonstrar o descuido que vem da ação de "jogar o lixo na rua". Com isso, considera-se a falta de consciência desta importância e a própria desvalorização das questões ambientais e da figura do catador de material reciclável.

Assim, o processo de escolarização vai se constituindo dos sonhos daqueles que não tiveram acesso à escolarização, os catadores de material de recicláveis como no relato da narrativa abaixo:

Antônio (11 anos): A minha mãe fala que ela manda eu sempre estudar para sê alguém na vida. Quando eu crescer né.

Ana (12 anos): meu pai veio para cá pra mim estudar, mas eu acho que ele qué $i$ embora de novo pro Pernambuco.

São mães e pais que buscam na ausência da escolarização uma justificativa de encaminhar seus filhos para escola. Sentem as alegrias do progresso e a tristeza de enxergar que alguns repetirão seus caminhos, irão abandonar a escola por não conseguirem conciliá-la com o trabalho. Esse grupo familiar produz o eco da escola, em uma constituição utópica de que é a partir daquele ambiente que eles irão transformar suas vidas, ter vidas diferentes das de seus pais.

\section{A escola e a lente do cotidiano}

A voz das crianças sempre trazia uma questão que inquietava. Quando falavam da escola, surgia a observação sobre atenção: "Ah tia, essa escola aqui tem que ter mais atenção, uma menina se perdeu" Rodrigo (12 anos). Ao explicarem o sentido da atenção, referiam-se ao cuidado, a estarem atentos a tudo naquele espaço. Esses casos aconteciam quando as crianças entravam em ônibus errados, ou desembarcavam na escola diferente ou se perdiam dentro do espaço da escola, situações que ocasionavam medo e insegurança devido às próprias características físicas do espaço.

Essas situações os levavam a trazer para as discussões e o desejo de uma escola mais atenta. Isso faz recortar ao que FrEIRE (1997) e Josso (2004) chamam de atenção consciente, atenta. Uma atenção que está relacionada à ação de ver o todo e, ao mesmo tempo, ver as parte que estão constituídas ali para possibilitar o diálogo. 
A ausência desta atenção incomoda e se torna eco nas conversas no decorrer das oficinas, ressaltando a necessidade de ser visto e ouvido.

A ausência da atenção aponta para a dificuldade da escola enxergar as diferenças contidas ali, se atendo somente aos conteúdos. Isso faz com que se crie uma lente em que se visualiza o conteúdo a ser vencido a cada bimestre. Com isso, as ações vão se tornando mecânicas, naturalizadas, pois o sistema valoriza as avaliações de grande escala. Assim, a escola vai constituindo um cotidiano de ausências. Ao dialogar com as professoras regentes das turmas, essas apontavam que a pesquisa Ihes trouxe elementos significativos para olharem aquele universo:

Profa Danielle: Parece que eles estavam escondidos em algum lugar aqui da escola e de repente esses meninos falam que os pais trabalham na reciclagem. Eles virão que não só eles, mas quase a escola toda. Não sei acho que isso de certa forma valorizou eles. Antes eles tinham muita vergonha de ser filho de catador.

Prof a Alinne: Bom eu sou retirante, descobri isso em uma matéria que fiz [...] Filha única, fui moradora de rua por um tempo grande, por isso que falo sobre o lanche, comer comida para quem passou muita fome é, pensa, muita fome [...] a minha vida, quer dizer, foi muito parecida com a deles.
São relatos que apontam o que o cotidiano escolar esconde, a constituição da vida de quem constitui esse universo que é a escola. Ao olharem para as histórias de vida desses estudantes, as professoras observaram que eram próximas das suas e continham diversas semelhanças. Isso as fazia enxergar a escola como um grupo de pessoas, algumas com contextos diferentes. Passavam a olhar para os estudantes como pessoas que carregavam uma determinada história e traziam elementos de identificação. A venda do cotidiano não estava somente nos olhos dos docentes, mas também nos olhos dos estudantes que enxergavam a lógica da escola somente a partir do olhar da lógica cognitiva. Escondiam a sua constituição, pois nessa organização não havia espaço para reconhecerem suas identidades.

Ao falarem de valores e saberes que não estão presentes na lógica escolar, descobrem que têm diversos pontos e trechos da sua vida que são comuns e isso passa a ser um valor. Percebem que, ao encontrarem outros que também vivenciaram aquele contexto, fortalecem-se. Olha para o outro com um sentimento de igualdade e reconhecimento do que seja viver em situações desfavoráveis, mas que estavam escondidas no cotidiano escolar. Situações que só se revelam quando há a construção de um lugar em que se possa dialogar sobre outra lógica, a lógica das vidas, dos saberes e viveres do cotidiano. 
Para alguns professores essa realidade se tornava de difícil compreensão, pois tinham consciência da realidade de alguns grupos, mas só haviam se aproximado dessa condição a partir da relação entre professor e estudante. Isso causava dores profundas, sentimento de impotência. Assim, no principio da relação protegiam-se com o distanciamento. Contudo, aos poucos iam se aproximando e compreendendo essa realidade pelo principio da abertura de acolher o outro e a si:

Norlene: Tudo pra mim é novo, tenho só três anos de Secretaria, nunca tinha trabalhado com eles. O primeiro ano foi assustador, mas a gente vai conversando, sabendo das coisas. Se apegando a eles sabe. Não é brincadeira a realidade desses meninos. Escutar pela mídia é uma coisa, mas viver isso tudo (se emociona).

O movimento de conversar e olhar para a escola, fez com que professores e estudantes refletissem sobre a condição individual e coletiva de cada ser pessoa. Isso trouxe a compreensão das diversas realidades que foram se encontrando naquele espaço/ tempo da escola e outras realidades que foram se constituindo a partir deste encontro. Alguns se encontravam em alguns pontos de suas histórias e experiências. Outros, contudo, se distanciavam isso os faziam serem conscientes da sua realidade e os o incentivavam a buscar um sentido naquele encontro produzido no espaço e no tempo da escola.
Os estudantes ao se assumirem como filhos de catadores, veem o espaço de poderem falar das suas próprias vidas e percebem que não são só suas, mas de muitos outros daquele contexto. Esse reconhecimento faz com que eles possam, além de se identificarem, identificarem outros e se tornarem grupo. Provavelmente seja essa a valorização que a professora Danielle se refere, pois, com o decorrer dos trabalhos alguns traziam listas com nomes de colegas que gostariam de participar das oficinas. Nesses momentos não havia mais a "vergonha". Seus contextos e suas histórias eram mostrados e assumidos. Reconheciam que não estavam solitários nesse aprender e conviver com o espaço escolar.

\section{O Olhar para um lugar chamado Estrutural}

A ida a Estrutural trazia diferentes comportamentos. Algumas crianças queriam que entrássemos nas casas, conhecêssemos sua família. Para outras, a passagem pelo ambiente familiar era rápida. Apresentavam os que estavam no momento e saiam. A justificativa para alguns era que: "Tia , é necessário ir no lixão, o principal né?" (João 12 anos). Esse argumento torna-se coerente para aqueles que não conheciam o lixão. Os que conheciam queriam apresentar a pesquisadora e aos outros, mas 
se observava que alguns grupos faziam visitas uns aos outros e, conheciam os familiares. Nesses casos a visita se prolongava.

Cada um deles gostaria de trazer uma foto que melhor apresentasse a sua cidade para ser levada a escola. Queriam mostrar que mesmo diante dos impactos ambientais da localização do Lixão, as pessoas que moram ali cuidavam do seu lixo e que os casos de violência muitas vezes retratado na mídia de massa, não retirava a liberdade das mães de passearem de bicicleta com seus filhos na rua. Esse olhar de positividade não os impediam de registrar os problemas. Algumas questões tinham relação com os impactos ambientais, outras com a ausência do Estado e conduziam a alguns enveredavam para o caminho da droga e do tráfico. Essas conversas iam surgindo no caminhar pela cidade.

O Lixão vai determinando o cenário ao redor, o fluxo do trânsito. Ao se aproximar do entardecer, esse fluxo torna-se arriscado, pessoas a pé e de bicicletas e diversas crianças atravessando as ruas, no percurso a onde passam as carretas.

Nesse local observou-se a dificuldade dos catadores que trabalhavam de forma independente quando são acometidos de problemas de saúde. O pai de Ramon relatava a preocupação de ficar sem o trabalho, pois tinha duas crianças para alimentar. Explicava que no momento só a esposa trabalhava, porque ele havia quebrado as duas pernas no trabalho no lixão. Sobrevive com o benefício concedido pelo Estado, mas a sua esposa trabalhava no Aterro todos os dias.

O grupo insistia em conversar sobre se poder conhecer um lugar denominado por eles de caminho de filme. Ao chegar no local a questão apresentada era a de buscarem modos de sentir o que esse caminho proporcionava:

Tadeu: "Tia aqui parece caminho de filme, é tão fresquinho".

Valda: "Aqui é muito bonito, olha lá" (apontando os vários pássaros).

Mariana: "Muito lindo! Dá vontade de ficar aqui, só ouvindo" (referindo-se ao canto dos pássaros).

Eles iam apreciando um espaço que para eles, naquele momento, trazia a percepção de estarem em um local natural. Era uma longa estrada de chão, na qual se avistavam várias chácaras. Estávamos em uma área rural da Estrutural, mas que se localizava ao lado do lixão. lam parando, pedindo para tirar fotos. Desciam, respiravam, pediam aos outros para silenciarem. No dia, já havia chovido e estava caindo aquela chuva bem fina. Uma das meninas pedia para que todos respirassem fundo para sentir o cheiro da chuva, relacionando com o cheiro da terra molhada. Assim, iam lançando olhares e apresentando o local com muito entusiasmo. 
Aos poucos, iam percebendo que o cenário ia sendo modificado, ouviam o barulho dos caminhões que estavam muito próximos. Voltaram a olhar a realidade do Aterro. De forma espantada, começaram a apontar e verbalizar que já trabalharam ali. Por alguns minutos, observou-se que eles vivenciavam um afastamento do local. Era como se a cada vez que se parou o carro para que descessem e fotografassem, eles pudessem vivenciar uma outra realidade de paisagem, mesmo que contemplativa. Havia um desejo que aquele momento se tornasse uma realidade local, com árvores e, cantar dos pássaros. O silêncio, mesmo que momentâneo, trouxe a cada um deles a calma, o que alguns verbalizavam como sendo um sentimento de paz e conexão com aquela natureza, que simboliza um ambiente natural. Observou-se em seus corpos uma calmaria que os tirou daquela realidade. A paisagem, no entanto, começa a mudar (Imagem 3).

A realidade da poluição estava próxima. Havia muito lixo jogado pelo chão. Eles

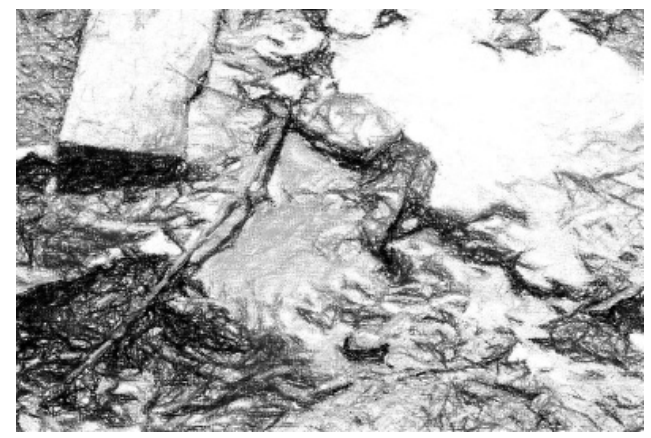

Imagem 3: Chorume derramando. Fonte: Produção Maria Flor, 10 anos demonstravam preocupações em especial com o que retrata a imagem do derramamento do chorume. O chorume escorria para bem próximos das chácaras, que eram locais em que se cultivavam hortaliças. A preocupação do grupo era em saber como impedir aquela situação. Reclamavam e contavam histórias de vizinhos que, ao trazer o material para casa, deixavam o rejeito (as sobras do que não serve para a comercialização) na rua. Pediram que, quando fossem reveladas as fotos, essas fossem entregues a eles, para poderem denunciar e quem sabe, levar para a Administração da cidade.

O andar com os colaboradores trouxe vários elementos significativos sobre suas histórias de vida, as relações com a escola e, em especial, sobre suas famílias. O papel da mãe em suas vidas é algo significativo. São crianças e adolescentes que enfrentam situações de conflitos no interior de suas famílias, mas veem na família um núcleo de segurança.

\section{Considerações}

Os estudantes filhos de catadores são conhecedores de sua realidade. Possuem um olhar crítico constituído por uma percepção consciente, mas simultaneamente positivo. Trazem questões coerentes sobre a realidade dos que vivem e sobrevivem nos Aterros, relações familiares, seus proces- 
sos de acesso a instituições que representam o Estado, como a escola, e o viver em seus lugares. Revelam questões de degradação socioambiental, emergindo a degradação da vida, mas alimentam a utopia da transformação, em que, diariamente, exercitam a luta dos seus pais. São apanhadores de sonhos na complexidade do viver.

Ao relatarem suas trajetórias de vidas e ao mesmo tempo refletirem sobre o espaço escolar, pode-se constatar que os estudantes vão identificando outros colegas que também vivem nas mesmas condições, o que contribui para o fortalecimento de sua identidade pessoal e coletiva e permite criar laços afetivos e potencializá-los. Dessa forma, a escola se converte em um espaço em que se pode dialogar, compartilhar histórias. Nesse processo, exercitam falar de seus sonhos, suas realidades, se reconhecem como capazes de aprender, apesar das limitações atribuídas a si mesmo. Vida e escola vão dando sentido uma a outra na busca de um diálogo em que ambas se alimentam e nutrem na direção de uma utopia para uma educação emancipada que os faça rever os modos de ser e habitar o planeta, e sua própria existência.

Assim, é necessário possibilitar instrumentos para dar voz aos estudantes e enxergar a escola e suas experiências de vida a partir dos seus olhares e das diversas formas de manifestá-lo. Com isso, pode-se provocar uma aprendizagem significativa, em que as dificuldades apresentadas sejam dialogadas por todo o grupo, em uma perspectiva de colaboração. Possibilitar o encontro e o fortalecimento dos grupos, como estratégias de potencializá- los a partir de uma educação baseada na formação humana e na leitura de mundo, em que se crie espaços de cooperação, de escuta e constituição de utopias baseadas na superação, na autoconsciência e na autonomia em que seja fundamental o trabalho com referenciais próximos à realidade vivida, como forma de reorientar e potencializar valores e a própria formação dos que a constituem.

\section{Referências bibliográficas}

ALTERTHUM, Camila Carvalhal. O encontro com crianças filhas de catadores de papel: sinalizações para uma creche e uma pesquisa com a "nossa cara". Belo horizonte, 2005. p.126 Dissertação (mestrado em Educação) - Universidade Federal de Minas Gerais; 2005.

BARBOZA, Daiani. As múltiplas cidades na cidade: as relações estéticas dos catadores de material reciclável com a polifonia urbana. Santa Catarina, 2013. 276p. Tese Doutorado em Psicologia. Universidade Federal de Santa Catarina; 2012.

CAVALCANTE, Andressa Lustosa. Os fatores que contribuem para o trabalho infantil no lixão da cidade Estrutural-DF - Brasília, 2014. 34p. Monografia apresentado ao curso de Graduação em Serviço Social. Universidade Católica de Brasília; 2014. Disponível em: <http://repositorio.ucb.br/jspui/handle/10869/4384>. Acesso: 10 jul. 2015.

FREIRE, Paulo. Pedagogia da Autonomia: saberes necessários à prática educativa. 6ed. Rio de janeiro. Paz e Terra. 1997.

JoSSO, Marie-Christine. As histórias como territórios simbólicos nos quais se exploram e se descobrem formas e sentidos múltiplos de uma existencialidade evolutiva singular-plural. In: PASSEGGI, M. C. (Org.). Tendências da pesquisa (auto) biográfica. Natal: EDUFRN; São Paulo, SP: Paulus, 2008. p. 23-50. 
PEREIRA, Maria izabel Galvão Gomes Pereira. Práticas educativas, territórios e biografização: reflexões a parti da educação rural. In: PASSEGGI, M. C. (Org.). Tendências da pesquisa (auto) biográfica. Natal: EDUFRN; São Paulo, SP: Paulus, 2008. p.145-164.

RICOEUR, Paul. Teoria da Interpretação. Lisboa: Edições 70 Ltda, 1976.

RICOEUR, Paul. O conflito das interpretações: ensaios de hermenêutica. Rio de Janeiro: Imago, 1978.

RICOEUR, Paul. Interpretações e ideologias. Rio de janeiro: livraria Francisco Alves, 1990.

RICOEUR, Paul. Tempo e Narrativa (Tomo I). São Paulo: Papirus, 1994.

RICOEUR, Paul. Tempo e narrativa (Tomo III). São Paulo: Papirus, 1997.

SOUZA, Elizeu Clementino. O conhecimento de si: narrativas do etinerário escolar e formação de professores. Bahia, 2004. 337 f. Tese Doutorado em Educação - Universidade Federal da Bahia; 2004. Disponível em: <https://repositorio.ufba.br/ri/bitstream/ri/10267/1/Tese_Elizeu\%20Souza.pdf.>. Acesso em: 10 jul. 2014.
SOUZA, Elizeu Clementino. A arte de contar e trocar experiências: reflexões teórico-metodológicas sobre história de vida em formação. Natal, 2006. Revista Educação em Questão. v. 25, n. 11, p. 22-39, jan./abr. 2006. Disponível em: <http://www.revistaeduquestao.educ.ufrn. br/pdfs/v25n11.pdf>. Acesso em: jun. 2015.

SOUZA, Elizeu Clementino; PASSEGGI, Maria da conceição. (Auto) biografia: Pesquisa e práticas de formação. Belo Horizonte 2011. Educação em Revista, vol.27, n.01. p.1-3. Disponível em: <http://www.scielo.br/scielo.php?script=sci_ar ttext\&pid=S010246982011000100014>. Acesso em: 15 jun. 2013.

VIEIRA, Cláudia Moraes da Costa. A práxis do viver como epistemologia: o saber sentido da/na escola como forma de emancipação da condição humana no viver na terra, 2016. 261f. Tese de Doutorado em Educação - Universidade de Brasília; 2016. Disponível em: http://repositorio.unb.br/handle/10482/21924 